\title{
Breaking the silence: ICT and the elderly in Malaysia
}

\begin{abstract}
This study investigates the pattern in using ICT amongst the elderly in Malaysia. 60 elderly people from two states in Malaysia participated in this study. A questionnaire was given to the elderly where the pattern of using the ICT would be found. The words or phrases used were identified and listed. Interview sessions were carried out to find out the number and balance of interaction while using the ICT. The model used for the nature and balance of interaction was developed by Normaliza Abd Rahim (2005). The results found that the elderly have positive interactions while using ICT. It is hoped that this study will help all the elderly in Malaysia to use the ICT to communicate.
\end{abstract}

Keyword: ICT, Elderly 